\title{
Morel-Lavallee lesion - radiological spectrum
}

\author{
Bharat Bhushan Sharma ${ }^{1}$, Sandeep Sharma ${ }^{2}$, Priya Ramchandran², Narendar Kumar Magu³ ${ }^{3}$ Mir Rizwan Aziz', \\ Shilpa Singh ${ }^{4}$
}

\author{
${ }^{1}$ Department of Radiodiagnosis, SGT Medical College, Gurgaon 122505, India. \\ ${ }^{2}$ Anaesthetics, Heartlands Hospital, Birmingham, West Midlands B9 555, UK. \\ ${ }^{3}$ Department of Orthopaedics, SGT Medical College, Gurgaon 122505, India \\ ${ }^{4}$ Faculty of Allied Health Sciences, SGT University, Gurgaon 122505, India.
}

Correspondence to: Dr. Bharat Bhushan Sharma, Department of Radiodiagnosis, SGT Medical College, Gurgaon 122505, India.

E-mail: bbhushan986@gmail.com

How to cite this article: Sharma BB, Sharma S, Ramchandran P, Magu NK, Aziz MR, Singh S. Morel-Lavalle lesion - radiological spectrum. Plast Aesthet Res 2016;3:335-8.

Article history:

Received: 10-08-2016

Accepted: 11-10-2016

Published: 25-10-2016

Key words:

Morel-Lavallee lesion,

haemolymph,

ultrasound,

magnetic resonance imaging

\section{ABSTRACT}

\begin{abstract}
Morel-Lavallee lesion (MLL) entity represents as a haemolymph mass as a result of closed degloving injury following focal trauma. The swelling can be mistaken as a tumor or simple hematoma formation, and it can be of concern as it gradually increases in size. It is important to diagnose the entity promptly as proper management can avoid skin necrosis and further complications. We present a 20 -year-old female nursing student who fell down from a scooter and developed painful massive right thigh swelling over a 3-week course following trauma. She underwent plain radiography which was unremarkable. Ultrasound and magnetic resonance imaging revealed the diagnosis of MLL and she was treated accordingly.
\end{abstract}

\section{INTRODUCTION}

Morel-Lavallee lesion (MLL) occurs when there is a collection of haemolymph due to the separation of skin and subcutaneous tissue from the underlying fascia. This usually happens after blunt trauma and patients present with progressive swelling and pain. The potential space formed by this separation of tissues is occupied by the oozing serous fluids like blood and lymph. This collection sometimes becomes encapsulated and does not resolve. VictorAuguste-Francois Morel-Lavallée ${ }^{[1]}$ a French surgeon described this entity first time in 1848.

\section{CASE REPORT}

A 20-year-old female reported to the orthopedic surgery department three weeks after falling from her scooter, with slightly painful swelling over the lateral aspect of the right thigh. The painful swelling increased progressively from small to massive size. On examination the site of the swelling was on the lateral aspect of the upper half of the right thigh. The swelling was soft and fluctuating, measuring approximately $15 \mathrm{~cm} \times 12 \mathrm{~cm}$ dimensions. Mild skin discoloration was present without open wounds [Figure 1].

cc) (1) This is an open access article distributed under the terms of the Creative Commons AttributioncC) Non NC SA Nommercial-ShareAlike 3.0 License, which allows others to remix, tweak, and build upon the work non-commercially, as long as the author is credited and the new creations are licensed under the identical terms. 

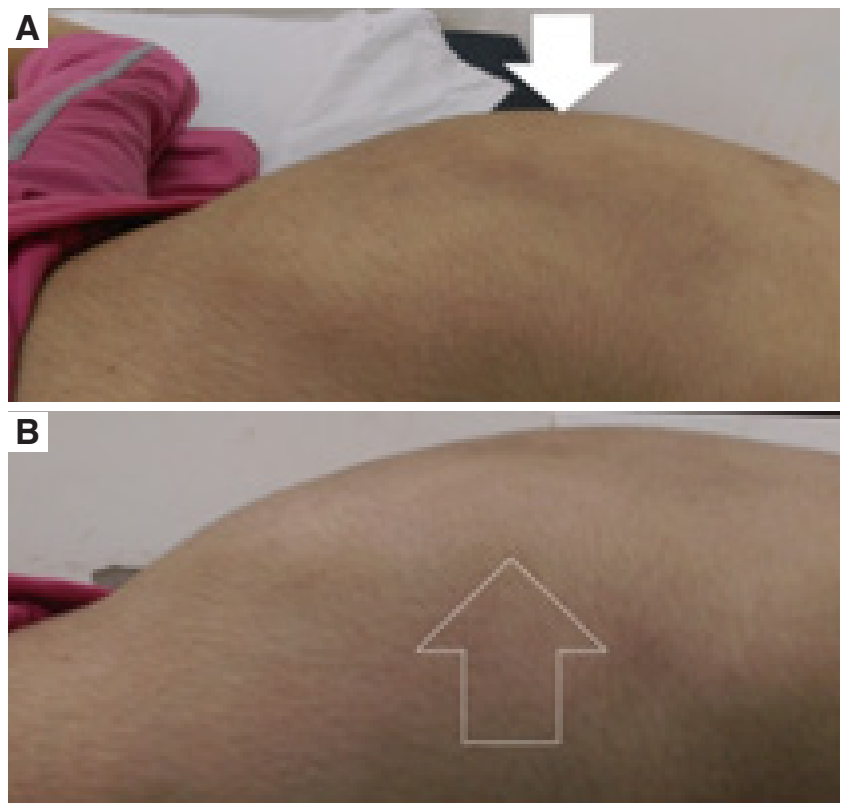

Figure 1: Photograph of the right leg with focal swelling. (A) frontolateral position of the thigh shows swelling on upper lateral part with slight discoloration (white solid arrow); (B) magnified view of the same swelling shows normal overlying skin surface (hollow white arrow)
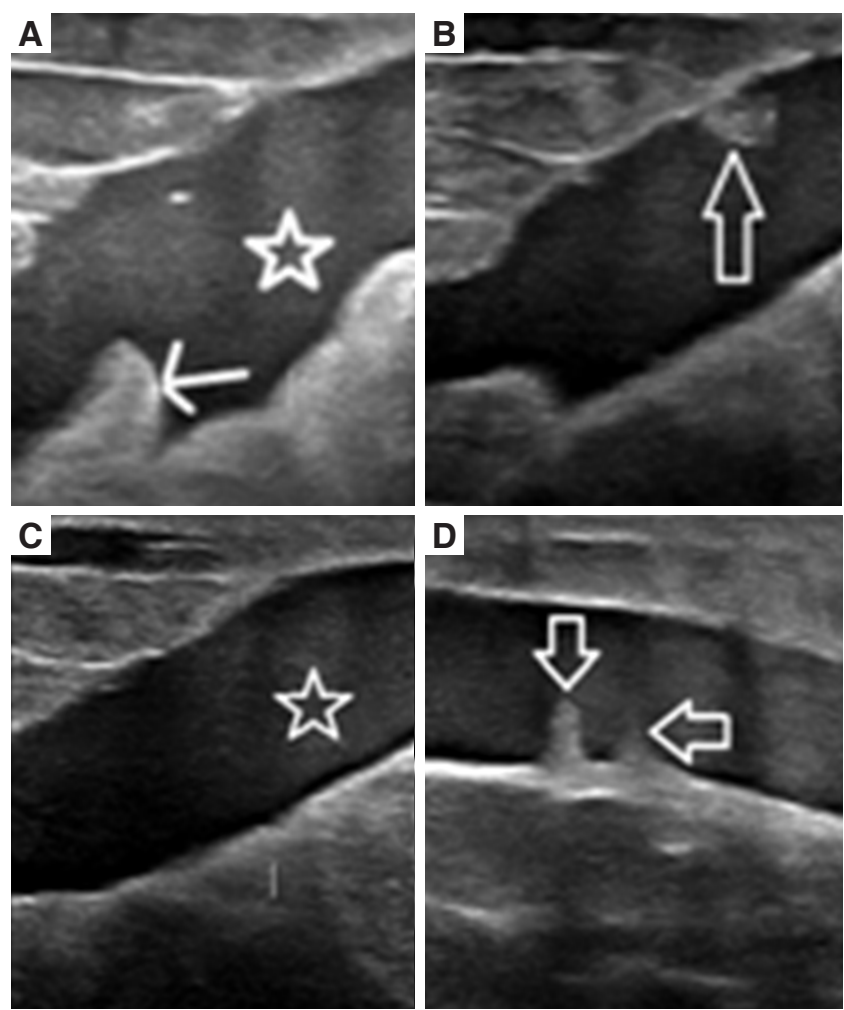

Figure 2: Greyscale images of the swelling with high frequency linear probe. (A) anechoic fluid in encapsulated space (white star) with echogenic fat lobule hanging against the margin (white arrow); (B) another similar image with fat lobule on the anterior aspect (upward arrow); (C) anechoic pure fluid in the space (white star); (D) two echogenic fat lobules (white arrows) hanging in the fluid

Plain X-ray of the right thigh and upper hip did not show any bony injury. Ultrasound (US) examination
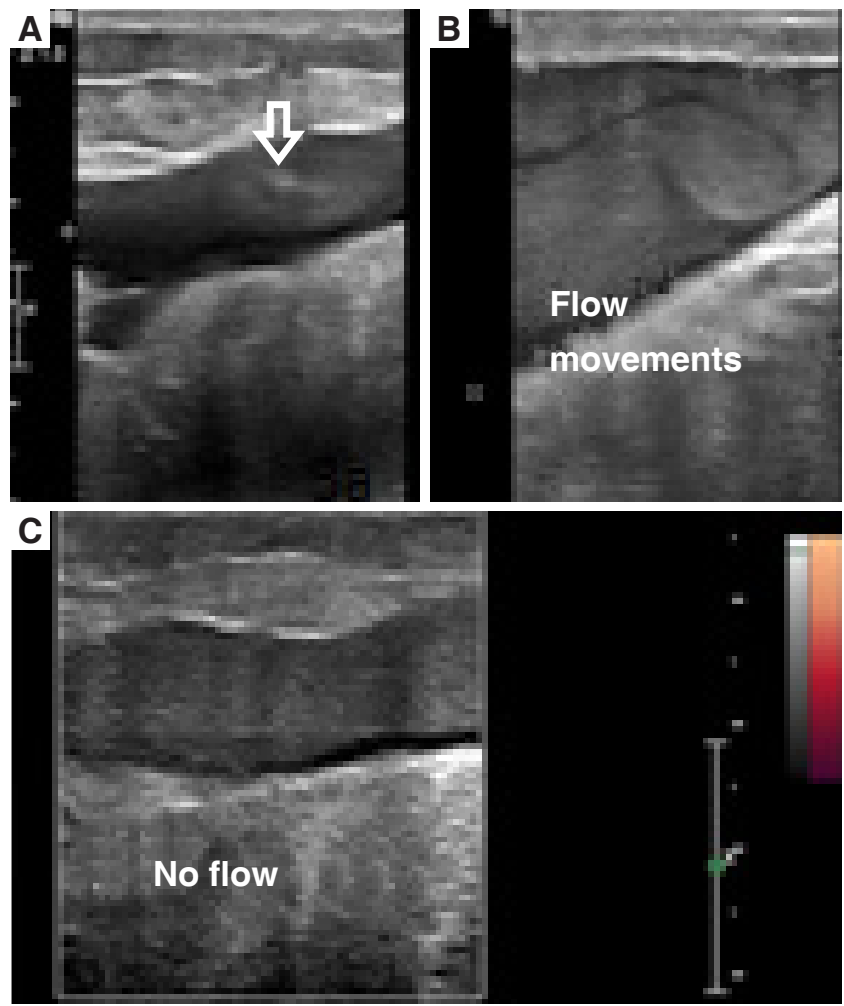

Figure 3: Ultrasound images showing the movement of the fluid. (A) few uniform soft echoes within the fluid (white arrow) because of haemolymph; (B) flow moments in the fluid because of different density of blood and lymph; (C) no color flow seen in and around the cycstic fluid in color flow imaging

was done with the high frequency linear probe for this swelling and showed predominantly anechoic collection seen under the skin soft tissue extending up to deep fascia without traversing it. A few echogenic foci were present within and at the periphery of the collection [Figure 2].

The movement of the fluid was seen while scanning after changing the position of the affected limb. There was no vascularity seen within the collection or from the edges of the swelling [Figure 3].

She underwent magnetic resonance imaging (MRI) and revealed the fluid collection underneath the skin but not extending into the deep fascia. The collection was hypointense on T1W and hyperintense on T2W sequences. T1W with fat suppression sequences showed suppression of the fatty lobules seen from the margins and inside the collection [Figure 4].

There was evidence of "fluid-fluid" levels seen within the swelling [Figure 5].

The patient was treated initially managed conservatively with no relief, and subsequently underwent surgical drainage with an uneventful recovery. The patient will 

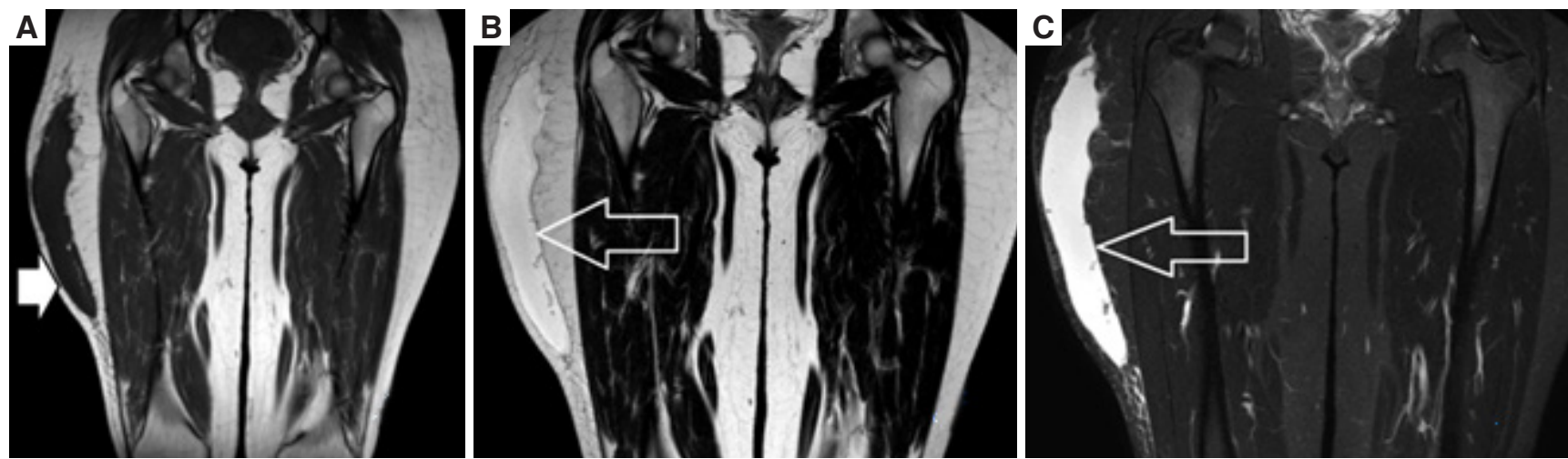

Figure 4: Magnetic resonance images. (A) T1W image shows hypointense collection under the skin but overlying the fascia (white arrow); (B) T2W image shows the collection as hyperintense with well defined margins (hollow white arrow); (C) STIR images reveal the collection as hyperintense with suppression of surrounding fat (hollow white arrow)
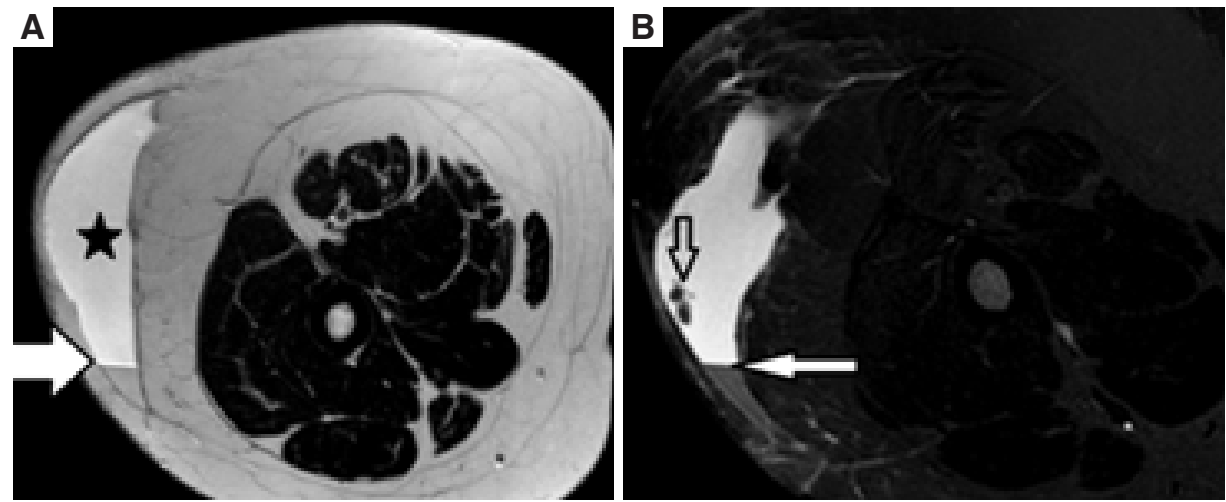

Figure 5: Magnetic resonance axial sections. (A) T2W image shows the "fluid-fluid level" (white solid arrow) within the collection (black star); (B) T2W fat suppressed image also shows the fat suppression of the fat lobule in the lumen (hollow black arrow). There is also the fluid-fluid level seen in the background of hyper intensity of the fluid and hypointensity of the old blood (white solid arrow)

be called for follow up to rule out any reaccummulation of the fluid.

\section{DISCUSSION}

MLL is a common condition and has got other names like post-traumatic soft tissue cyst or pseudolipoma. Post traumatic swelling of soft tissues is not uncommon and this can be misleading when degloving injury is present. The underlying mechanism is very simple as the small vessels and lymphatics are torn due to disruption of the skin layer from the underlying fascia by the direct and tangential forces. The fluid accumulates in this potential space and presents as swelling on the affected region. ${ }^{[2]}$ The most common place is on the lateral aspect of the greater trochanter but can happen anywhere on the thigh. These swellings can either subside because of absorption of fluid or become encapsulated. These can also become infected and there is a potential for overlying skin necrosis. ${ }^{[3]}$ The collected fluid is usually serosanguinous in nature. The septation and fat globules can also be seen in some swellings as it was in our case. These lesions may be associated with fractures, and may form a capsule with unchanged size. Swellings of longer duration can be mistaken for soft tissue tumors and therefore have to be differentiated from sarcoma, haemangioma and fat necrosis. US imaging is characteristic of MLL as anechoic lesions with or without fat globules within it. ${ }^{[4]}$ Color flow imaging does not show any vascularity or feeding vessels. Noncontrast computed tomography of the thigh shows fluid-fluid level because of the different density of the blood and other fluid. MRI is the modality of choice for delineation of the lesions. This can differentiates the fluid contents and underlying fascia. The fat globules seen in the lesion can easily be confirmed by fat suppression sequences. ${ }^{[5,6]}$ The differential diagnosis of these lesions is haemangioma, fat necrosis, sarcoma or simple subcutaneous hematoma formation. The management is dependent on the size, location and the duration of the lesion. ${ }^{[7]}$ Conservative management is advocated for smaller lesions without presence of septations and infection. ${ }^{[8]}$ Lesions with capsule and septations require surgical drainage. Post surgical graduated compression by stocking prevent the reaccumulation of the collection by agglutinating the skin to underlying fascia. ${ }^{[9]}$ 
In conclusion, the diagnosis of MLL is of great importance as the management depends upon the nature and size of collection. Radiological assessment like US and MRI play a major role in the diagnosis and treatment of the lesion. As recurrence is very common, graduated compression stocking should be worn until follow-up. Careful management will avoid skin necrosis and other associated complications.

\section{Financial support and sponsorship}

None.

\section{Conflicts of interest}

There are no conflicts of interest.

\section{Patient consent}

The proper consent of the patient was taken for carrying out all the tests and management.

\section{Ethics approval}

The approval for publishing this case had been taken from the institute board of SGT Medical College.

\section{REFERENCES}

1. Morel-Lavallee VAF. Decollements traumatiques de la peau et des couches sous-jacentes. Arch Gen Med 1863;1:20-38,172-200,300332. (in French)

2. Parra JA, Fernandez MA, Encinas B, Rico M. Morel-Lavallée effusions in the thigh. Skeletal Radiol 1997;26:239-41.

3. Li H, Zhang F, Lei G. Morel-Lavallee lesion. Chin Med J (Engl) 2014;127:1351-6.

4. Goodman BS, Smith MT, Mallempati S, Nuthakki P. A comparison of ultrasound and magnetic resonance imaging findings of a MorelLavallee lesion of the knee. PM R 2013;5:70-3.

5. Mallado JM, Bencardino JT. Morel-Lavallée lesion: review with emphasis on MR imaging. Magn Reson Imaging Clin N Am 2005;13:775-82.

6. Gilbert BC, Bui-Mansfield LT, Dejong S. MRI of a Morel-Lavellée lesion. AJR Am J Roentgenol 2004;182:1347-8.

7. Hak DJ, Olson SA, Matta JM. Diagnosis and management of closed internal degloving injuries associated with pelvic and acetabular fractures: the Morel-Lavallée lesion. J Trauma 1997;42:1046-51.

8. Hudson DA, Knottenbelt JD, Krige JE. Closed degloving injuries: results following conservative surgery. Plast Reconstr Surg 1992;89:853-5.

9. Harma A, Inan M, Ertem K. The Morel-Lavallée lesion: a conservative approach to closed degloving injuries. Acta Orthop Traumtol Turc 2004;38:270-3. 